\title{
In Defense of Direct Action
}

\author{
Ivar Hardman (pseudonym)
}

Submitted: 6 May 2020, accepted: 31 March 2021, published: 25 April 2021

\begin{abstract}
There is widespread agreement that coercive force may be used to prevent people from seriously and wrongfully harming others. But what about when those others are non-human animals? Some militant animal rights activists endorse the use of violent coercion against those who would otherwise harm animals. In the philosophical literature on animal ethics, however, theirs is a stance that enjoys little direct support. I contend that such coercion is nevertheless prima facie morally permissible. I defend this contention by arguing (a) that from the point of view of common sense morality, it is prima facie permissible to use coercive force to prevent puppies from being wrongfully mutilated and (b) that this point clearly extends to other kinds of animals and to other kinds of seriously harmful practices. I then show that there is, as a result of (b), presumptive moral justification for some of the highly controversial instances of direct action undertaken by the Animal Liberation Front and similar groups of militant animal rights activists. I close by arguing that pragmatic considerations override most proposals to undertake direct action, even when the proposed actions are prima facie morally permissible. Indeed, I conclude that although the use of violent coercion to prevent harm to animals may occasionally be ultima facie permissible, its use is in tension with (and tends to undermine) the broader agenda of the animal rights movement.
\end{abstract}

Keywords: Alastair Norcross; animal ethics; animal liberation front; common sense morality; direct action; animal experimentation; civil disobedience; abnegation

How to cite: Hardman, I. (pseudonym) In Defense of Direct Action. Journal of Controversial Ideas 2021, 1(1), 2; doi:10.35995/jci01010002.

(C) 2021 Copyright by the author. This article is an open access article distributed under the terms and conditions of the Creative Commons Attribution (CC BY 4.0) license.

(c) (1)

\section{Introduction}

There is widespread agreement that coercive force may be used, even by non-state actors, to prevent people from wrongfully inflicting serious harm upon others. But what about when those others are non-human animals? Some militant animal rights activists endorse the use of coercion-understood to include violence, threat of violence, and physical restraint-against those who would otherwise seriously and wrongfully harm animals. ${ }^{1}$

1 When I use 'animal rights', the term 'rights' is not meant to be philosophically substantive or to assume any particular theory or characterization of moral rights. For instance, I use 'animal rights movement' as 
In the philosophical literature on animal ethics, however, theirs is a stance that enjoys little direct support, even from those who advance species egalitarian positions. ${ }^{2}$ Indeed, Peter Singer and Tom Regan, no doubt the two leading figures in that literature, are inclined to oppose such uses of coercion. ${ }^{3}$ I contend, in contrast, that the use of coercion against those who would otherwise seriously and wrongfully harm animals is prima facie (or pro tanto) morally permissible. ${ }^{4}$

Here is an argument for my position:

(1) It is prima facie morally permissible to use coercion to prevent puppies from being seriously and wrongfully harmed.

(2) There is no morally salient difference between puppies and other mammals.

(3) Thus, it is prima facie morally permissible to use coercion to prevent mammals from being seriously and wrongfully harmed.

(4) When mammals such as cows, pigs, sheep, and mice are turned into food, clothing, or experimental research subjects, they are, in most instances, seriously and wrongfully harmed.

(5) Thus, it is prima facie morally permissible, in most instances, to use coercion to prevent mammals such as cows, pigs, sheep, and mice from being turned into food, clothing, or experimental research subjects.

a mere paraphrase for "the movement to secure moral recognition for and prevent wrongful treatment of animals."

2 Aside from Steve Best, no contemporary philosophers have, to my knowledge, directly and explicitly defended, even to a limited degree, the moral permissibility of using coercion against those who would otherwise seriously and wrongfully harm animals. See Steve Best, "It's War," in Terrorists or Freedom Fighters: Reflections on Animal Liberation, eds. Steve Best and Anthony Nocella (New York: Lantern Books, 2004), 300-40. Moreover, Best's defense of coercive tactics is situated within a polemical argument for revolutionary political violence that aims at a profound reordering of human social and political life. Best (ibid., 335) assumes, for instance, that "the animal rights community can no longer afford to be a single-issue movement, for now in order to fight for animal rights we have to fight for democracy." Indeed, Best's political project is broader in scope and more radical in character than the kinds of political projects ordinarily championed by animal rights activists and the philosophers who share their convictions. For other work that addresses issues adjacent to those discussed in this essay see: Ned Hettinger, "Environmental Disobedience," in A Companion to Environmental Philosophy, ed. Dale Jamieson (Oxford: Blackwell, 2001), 498-509; Steve Cooke, "Animal Rights and Environmental Terrorism," Journal of Terrorism Research 4 (2013): 26-36; John Hadley, "Animal Rights and Self-Defense Theory," Journal of Value Inquiry 43 (2009): 165-77; CE Abbate, "The Search for Liability in the Defensive Killing of Nonhuman Animals," Social Theory and Practice 41 (2015): 106-30; Michael Allen and Erica von Essen, "Are Illegal Direct Actions by Animal Rights Activists Ethically Vigilante," Between the Species 22 (2018): 260-85. All of these papers make interesting contributions to the literature, but none presents a direct and unequivocal argument for the moral permissibility of using coercion to defend animals against wrongful harm.

3 I purposefully use the phrase 'inclined to oppose' rather than more direct language. This is because both Singer and Regan have been guarded in their pronouncements on this subject. For their tacit opposition, see, for example: Peter Singer, "Introduction," in In Defense of Animals: The Second Wave, ed. Peter Singer (New York: Wiley, 2006), 1-10; Tom Regan, "How to Justify Violence," in Terrorists or Freedom Fighters: Reflections on Animal Liberation, eds. Steve Best and Anthony Nocella (New York: Lantern Books, 2004), 231-36.

4 In what follows, I use 'animal' to pick out all and only mammals, although I often use the former term for stylistic reasons. I restrict my argument to mammals because doing so makes its key premises easier to defend. This is because there is widespread agreement that mammals are sentient. Furthermore, it is not uncommon to assign them some degree of self-awareness (although this is a more controversial position). Both of these attributes are ordinarily taken to be sufficient for possession of moral status. 
In what follows, I take premises (2) and (4) for granted (although considerations adduced in sections three and four support these premises). ${ }^{5}$ After briefly clarifying my terminology in section one, I devote section two to the task of defending premise (1). I do this by appealing to an example from a widely anthologized essay by Alastair Norcross. ${ }^{6}$ I then develop several variants of Norcross' example in order to explore the conditions under which different kinds of coercion might be permissibly employed to prevent people from seriously and wrongfully harming puppies. After consideration of these new cases, I conclude that pre-theoretic judgments of common sense morality justify premise (1) and, by extension, that common sense morality is committed to the prima facie permissibility of using coercive force-including violence, threat of violence, physical restraint, and property damage-against those who would otherwise seriously and wrongfully harm animals. In the remaining sections, I draw out some of the implications of my conclusion and defend it against objections.

In section three, I respond to objections focused on the putative limitations and artificiality of my initial cases. I do this by describing several additional cases, some hypothetical and some actual (including an instance of direct action carried out by the Animal Liberation Front), and arguing that the use of coercion is prima facie permissible in all of them. In section four, I review and rebut two objections to the use of coercion against institutions and individuals engaged in wrongful animal experimentation. In section five, I argue that pragmatic considerations weigh heavily against the use of coercion by animal rights activists, even in cases where its use is prima facie permissible. Although the use of coercion is sometimes ultima facie morally permissible, I conclude that it is rarely an appropriate tactic for those concerned with advancing the broader agenda of the animal rights movement.

\section{Section One}

The first premise of my argument states that it is prima facie morally permissible to use coercion to prevent puppies from being seriously and wrongfully harmed. Before I defend this premise, some terminological clarification is in order.

First, I use 'prima facie morally permissible' to denote actions that are permissible absent the presence of overriding moral reasons. Thus, to say that action a is prima facie morally permissible in circumstance $c$ is to say that it is not morally wrong for $S$ to perform $a$ in $c$ unless $S$ has an overriding moral reason that precludes the performance of $a$. An overriding moral reason is a moral reason that $S$ is required to act upon in $c$.

5 Support for premise (2) can be found in numerous philosophical works, including: Peter Singer, Animal Liberation (New York: Harper Collins, 2002); Tom Regan, "Empty Cages: Animals Rights and Vivisection," in Contemporary Debates in Applied Ethics, eds. Andrew I. Cohen and Christopher Heath Wellman (Malden, MA: Blackwell, 2019), 77-90; Mylan Engel, "The Commonsense Case for Ethical Vegetarianism," Between the Species 19 (2016): 2-31. Support for premise (4) can be found in numerous philosophical works, including: Singer, Animal Liberation; Regan, "Empty Cages"; Mylan Engel, "The Commonsense Case against Animal Experimentation," in The Ethics of Animal Research, ed. Jeremy Garrett (Cambridge, MA: MIT Press, 2012), 215-36. I regard it as beyond dispute that most common animal rearing, slaughter, and experimentation practices seriously and wrongfully harm animals. Confinement, mutilation, and death are, in most instances, seriously harmful. And, granting the possible exception of some harms imposed by medical researchers, these harms are imposed unnecessarily and therefore wrongfully.

6 Alastair Norcross, "Puppies, Pigs, and People: Eating Meat and Marginal Cases," Philosophical Perspectives 18 (2004): 229-45. 
Second, I define 'coercion' as the use or threat of violence (understood broadly to include forceful physical restraint and imprisonment) against persons or their property with the purpose of altering what the targeted individuals are able or willing to do. This definition is stipulative. There is a significant philosophical literature devoted to the analysis of the concept of coercion. ${ }^{7}$ I introduce a stipulative definition in order to sidestep debates about the necessary and sufficient conditions for the correct use of this concept in ordinary discourse. Such debates are largely orthogonal to the views I advance in this essay. My aim is to defend the contentious claim that people may use or threaten violence against those who would otherwise seriously and wrongfully harm animals. It is not to engage in conceptual analysis.

For this reason, I will also not attempt to analyze or theoretically define 'violence', 'threat', or 'serious harm.' The instances of violence, threat making, and serious harm discussed below are paradigm cases. Thus, there is no need to provide definitions that settle debates about marginal cases. I also leave 'wrongful harm' at the intuitive level, although I believe that the harms discussed in the cases below all satisfy a sufficient condition for the harm to count as wrongful-namely, that it is inflicted for no good reason.

I include violence against property in my definition of coercion in order to sidestep another linguistic debate. Some animal rights activists think that only sentient beings can be the targets of violence. They conclude, on that basis, that property damage counts as nonviolent activism. ${ }^{8}$ Others think this view is inconsistent with the ordinary use of 'violence.' As I see it, quibbling over how to properly define 'violence' does little to address the substantive question taken up below-namely, whether or not it is (even prima facie) morally permissible to damage or destroy property in order to prevent animals from being seriously and wrongfully harmed.

In several places, especially in sections four and five, I use the phrase 'coercive direct action' to describe the forms of violence under consideration. My use of the modifier 'coercive' conforms to the stipulative definition of 'coercion' presented above. I use 'direct action' to refer to a broad class of social protest activities that, roughly, violate the legal and/or community norms governing such activities; examples include: the heckler's veto, sit-ins, traffic blockades, trespassing protests, sabotage, property destruction, arson, and street fighting. I will not attempt to further analyze or define 'direct action.' I use the phrase because it is part of the common lexicon of militant animal rights activists. These activists typically describe their animal rescues and acts of property destruction as instances of direct action, which they contrast with more conventional forms of protest. ${ }^{9}$ I intend to show that, regardless of how they are best described or categorized, some forms of social protest activity that are norm-violating because they involve coercion are nevertheless prima facie morally permissible when used to defend animals.

7 This literature begins with Robert Nozick, "Coercion," in Philosophy, Science, and Method: Essays in Honor of Ernest Nagel, eds. Sidney Morgenbesser, Patrick Suppes and Morton White (New York: St. Martin's Press), 440-72.

8 For more on this linguistic debate, see: Steve Best and Anthony Nocella, "Introduction," in Terrorists or Freedom Fighters: Reflections on Animal Liberation, eds. Steve Best and Anthony Nocella (New York: Lantern Books, 2004), 30-34.

9 For instance, although they claim to use only nonviolent tactics, one prominent group of militant activists operate under the name Direct Action Everywhere. Their website is www.directactioneverywhere.com. 


\section{Section Two}

In the essay "Puppies, Pigs, and People," Alastair Norcross produces a rather memorable thought experiment centered upon a dispossessed chocolate lover named Fred. Norcross writes:

"... Fred ... receives a visit from the police one day. They have been summoned by Fred's neighbors, who have been disturbed by strange sounds emanating from Fred's basement. When they enter the basement they are confronted by the following scene: Twenty-six small wire cages, each containing a puppy, some whining, some whimpering, some howling. The puppies range in age from newborn to about six months. Many of them show signs of mutilation. Urine and feces cover the bottoms of the cages and the basement floor. Fred explains that he keeps the puppies for twenty-six weeks, and then butchers them while holding them upside-down. During their lives he performs a series of mutilations on them, such as slicing off their noses and their paws with a hot knife, all without any form of anesthesia. Except for the mutilations, the puppies are never allowed out of the cages, which are barely big enough to hold them at twenty-six weeks. The police are horrified, and promptly charge Fred with animal abuse ... "10

Norcross further develops the thought experiment over several lengthy paragraphs. Here is a brief summary: Fred attempts to justify his behavior by explaining its ultimate aim-namely, to enable him to enjoy the taste of chocolate, which is one of his great passions. Due to a head injury, Fred can only enjoy chocolate when its consumption is supplemented with a flavor enhancing hormone that is no longer produced by his body. The one known replacement hormone is secreted by puppies, but only when they experience prolonged and excruciating pain. Thus, Fred devises the scheme described above as a means by which to acquire the needed hormone. His behavior is not sadistic, he claims, but in keeping with the morally benign norms of mainstream gastronomy.

While Norcross uses the story of Fred to draw an analogy between mutilating puppies and consumer support of factory farming, I should like to use it to defend the first premise of my argument. Once again, this premise states: It is prima facie morally permissible to use coercion to prevent puppies from being seriously and wrongfully harmed. Notice that the intuition that Fred should be stopped is implicit in Norcross' example. Indeed, the example begins with a police visit and ends with Fred being placed under arrest. In this case, the state uses coercive force to prevent Fred from continuing to wrongfully harm animals. And it is hardly controversial to hold that the state is within its rights to arrest and prosecute him. ${ }^{11}$

Anyone who thinks that the state should be able to detain, imprison, or otherwise interfere with people to stop them from seriously and wrongfully harming puppies is already committed to the view that coercive force may be used to defend the interests of at least some animals. Of course, we are often prepared to grant the state special coercive powers that we would not grant to individuals. Thus, to fully support premise (1),

10 Norcross, "Puppies, Pigs, and People," 229.

11 Although there is debate about the details, there is a near consensus that animals should receive some degree of legislative protection. For instance, a recent Gallop poll shows that only 3\% of Americans believe that "animals don't need much protection from harm and exploitation, since they are just animals." See: Rebecca Rifkin, "In U.S., More Say Animals Should Have Same Rights as People," Gallup, May 18, 2015, http://www.gallup.com/poll/183275/say-animals-rights-people.aspx. 
I need to provide justification for the claim that non-state actors are also permitted to use coercion to prevent puppies from being seriously and wrongfully harmed.

Although there is a strong presumption against the use of coercive force by private citizens, this presumption is overridden in cases where its use prevents significant harm to which a victim is not liable and has not consented. For instance, we judge that it is permissible for a civilian to forcibly disarm and detain an intoxicated gunman who is attempting to perform trick shots in a densely populated area. When we reflect on cases in which coercive interference by private citizens can be used to prevent significant harm to puppies, we reach similar conclusions.

To see this, consider two variations of Norcross' thought experiment:

F2: Fred's neighbor Jim hears anguished cries emanating from Fred's basement. As a result, Jim becomes concerned and decides to peek through one of Fred's basement windows. What he sees is shocking. Fred is using a small knife to slowly mutilate a puppy, whose body is suspended upside-down from the basement ceiling. Jim quickly concludes that something must be done. He breaks into Fred's house, rushes to the basement, and physically subdues Fred. After tying Fred to a support beam in the basement, Jim calls the police.

F3: As in F2, Jim witnesses the scene taking place in Fred's basement. He concludes that something must be done. Jim does not believe that he can physically subdue Fred, but he does happen to be carrying a firearm. Thus, Jim breaks into Fred's house, rushes to the basement, draws his pistol, and yells "Stop that or I'll shoot." After convincing Fred to tie himself to a support beam in the basement, Jim calls the police.

I expect readers will share my judgment that, given the imminent threat Fred poses to the puppies in his care, Jim's behavior in these cases is prima facie morally permissible. Indeed, I hold that this is a pre-theoretic judgment of common sense morality. ${ }^{12}$

It is pre-theoretic because it is not inferred from and does not rest upon a prior commitment to any particular normative ethical theory. Someone who has never thought about moral philosophy in a systematic way can still be expected to arrive at this judgment when reflecting upon cases F2 and F3 (I grant, of course, that they are unlikely to express this judgment by using the language of prima facie moral permissibility). In just the same way, someone who has never thought about moral philosophy in a systematic way can still be expected to judge, as Renford Bambrough (1969) suggests, that this child, who is about to undergo what would otherwise be painful surgery, should be given an anesthetic before the operation. ${ }^{13}$ One needs no moral theory to provide the intellectual scaffolding for these judgments.

12 I adopt the operative notion of common sense morality from Michael Huemer, who says that it consists of a collection of judgments about particular cases and non-theoretical general principles that "the great majority of people are inclined to accept, especially in my society and societies that readers ... are likely to belong to." See: Michael Huemer, The Problem of Political Authority (New York: Palgrave, 2013), 15. Huemer also makes a similar point about coercion: "In common sense morality ... coercion requires a justification...one legitimate justification is self-defense or defense of innocent third parties: one may harmfully coerce another person, if doing so is necessary to prevent that person from wrongfully harming someone else." See: ibid., 10.

13 Renford Bambrough, "A Proof of the Objectivity of Morals," American Journal of Jurisprudence 14 (1969): 37-53. 
The conclusion that Jim's behavior in F2 and F3 is prima facie permissible is a judgment of common sense morality insofar as it is embedded in a collection of widely shared and confidently held moral attitudes. ${ }^{14}$ These concern both particular cases (for instance, it was wrong, given the circumstances, for Ray to steal Kyle's food) and action types (for instance, theft is wrong, cheating on a test is wrong, helping those in need is commendable). From the point of view of common sense morality, coercion is permissible when it is used to defend potential victims of serious and wrongful harm. And puppies are taken to be worthy of defense. ${ }^{15}$ We use the pre-theoretic judgments of common sense morality to construct and evaluate our moral and political theories and principles. Although these judgments are not incontrovertible or unrevisable, they are our theoretical building blocks and thereby carry a presumption of accuracy. ${ }^{16}$

Now, it is clear enough that Jim's behaviors in F2 and F3 are coercive. In the first case, he uses physical force to alter what Fred is able to do. In the second, Jim uses the threat of serious and violent harm to influence Fred's behavior. Thus, our judgments about F2 and F3 are sufficient to provisionally justify a reading of premise (1) that includes the behavior of private citizens within its scope.

Even if premise (1) is justified, however, it does not follow that any form of coercion that would prevent serious and wrongful harm to puppies is thereby prima facie morally permissible. Jim's actions in F2 and F3 meet the standards set by common sense morality for the necessity and proportionality of forcible harm prevention. ${ }^{17}$ Since the threat to the

14 In my view, our judgments about F2 and F3 are also immediate, in the sense that we do not arrive at them by conscious inference from other beliefs. For this reason, I would categorize them as moral intuitions. I follow Jeff McMahan in thinking that "a moral intuition is a moral judgment-typically about a particular problem, a particular act, or a particular agent, though possibly also about a moral rule or principle-that is not the result of inferential reasoning. It is not inferred from one's other beliefs but arises on its own. If I consider the act of torturing the cat, I judge immediately that, in the circumstances, this would be wrong." See: Jeff McMahan, "Moral Intuition," in The Blackwell Guide to Ethical Theory, eds. Hugh LaFollette and Ingmar Persson (Oxford: Blackwell, 2013), 104-5. Perhaps more controversially, I also think we are prima facie justified in endorsing the contents of these intuitions simply in virtue of the fact that they appear to us to be true. For a defense of this position see: Michael Huemer, Ethical Intuitionism (New York: Palgrave, 2005). Since I do not think they have direct bearing on the central arguments of this essay, I will not attempt to defend my views about the immediacy of or the source of justification for our judgments about F2 and F3. I make these views explicit in order to provide the reader with a better sense of the epistemological background commitments that influence my understanding of common sense morality.

15 See, once again, Rifkin, "More Say Animals Should Have Same Rights ..."

16 Indeed, as Huemer notes, "every [inquiry] must begin somewhere, and beginning with such [common sense judgments] as that under normal conditions one may not rob, kill, or attack other people seems reasonable enough. This is about the least controversial, least dubious starting point...I have seen." See Huemer, The Problem of Political Authority, 179. Readers may also wish to compare my discussion of "judgments of common sense morality" with Timmons' "considered moral beliefs" and Cuneo and Shafer-Landau's "moral fixed points." See: Mark Timmons, Moral Theory: An Introduction (New York: Roman and Littlefield, 2002); Terence Cuneo and Russ Shafer-Landau, "The Moral Fixed Points: New Directions for Moral Non-naturalism," Philosophical Studies 171 (2014): 399-443.

17 The recent philosophical literature contains a wealth of material on self- and other-defense. Some highlights include: JJ Thomson, "Self-Defense," Philosophy and Public Affairs 20 (1991): 283-310; Jeff McMahan, Killing in War (Oxford: Oxford University Press, 2009); Seth Lazar, "Necessity in Self-Defense and War," Philosophy and Public Affairs 40 (2012): 3-44; Helen Frowe, Defensive Killing (Oxford: Oxford University Press, 2014). Much of this material has bearing on my claims about the necessity and proportionality of the coercion Jim employs in F2 and F3. This material is also relevant to the examples I describe and claims I make in sections three, four, and five. Some contributors to this literature-including Hadley, "Animal Rights and Self-Defense Theory" and Abbate, "The Search for Liability"-have even explored the applicability of self-defense theory to issues in animal ethics. Even so, I will not directly engage with this literature. A central aim of this paper is to show that we need only appeal 
puppies is imminent, Jim does not appear to have an alternative means to stop Fred. But he uses only as much coercion as is needed to incapacitate Fred and end the threat.

By contrast, it is not morally permissible to undertake a campaign of killing arbitrarily chosen victims in order to somehow prevent the mutilation of puppies. Nor is it permissible to threaten extreme retributive violence against the family members of someone who is in the business of wrongfully harming puppies. Thus, since there are limits on the kinds of coercion common sense morality will countenance, we should consider an additional case before concluding this section. This case is designed to prompt reflection about the permissibility of property damage, which is one of the main forms of coercion employed by militant animal rights activists.

F4: As in F2 and F3, Jim witnesses puppies being mutilated in Fred's basement. He concludes that something must be done. He opts to call the police. When they arrive, however, the lead officer informs Jim there is nothing she can do to stop Fred from mutilating the puppies caged in his basement. Although the officer confesses that she finds Fred's behavior abhorrent, it turns out that the animal protection laws in Jim's city have a loophole that exempts all animals that are used in ongoing medical research or treatment from consideration. Fred is aware of this loophole. Thus, although his aim is to merely extract a flavor enhancer with no special medicinal properties, he has procured letters of support from his physician and a medical researcher at the local university. Both letters attest to the medicinal and therapeutic value of the hormone Fred is collecting. Although these letters of support may not hold up under legal or scientific scrutiny, any adjudication process promises to be lengthy. Thus, the police leave Fred to continue his puppy mutilation and tell Jim to contact the district attorney's office if he wants to take the matter further.

When Fred leaves for work the next morning, Jim breaks into his house, rescues the puppies in his basement, and then destroys Fred's equipment, files, research notes, and everything else that appears to support the ongoing project of puppy mutilation. Then, he breaks a sewage pipe. This floods the basement with rancid water and renders it unusable for the foreseeable future.

Jim's behavior in F4 is clearly coercive. It involves theft, trespassing, and property destruction that jointly alter what Fred is able and/or willing to do. Although this case is more complex than F2 or F3, I expect readers will share my judgment that Jim's behavior in F4 is prima facie morally permissible. Although the puppies Jim rescues do not face an immediate threat, his actions prevent them from being seriously and wrongfully harmed in the near future. Furthermore, Jim's destruction of Fred's workspace and tools pre-emptively prevents the mutilation of the replacement puppies that Fred would otherwise procure (given the state's reluctance to interfere with his scheme). At least

to common sense morality to defend the prima facie permissibility of using coercion against those who would otherwise harm animals. Thus, I do not want the claims I defend to be conditional on the acceptance of specific theoretical commitments concerning self- and other-defense or specific philosophical analyses of such notions as necessity, proportionality, and liability. Indeed, rather than taking a top down approach focused on applying theoretical principles and analyses to the examples under consideration, I take a bottom up approach focused on eliciting intuitions about specific cases. These intuitions can then be used to support more general theoretical claims. Going forward, I make no assumptions, aside from those I believe to be embedded in common sense morality, concerning the conditions under which an agent is liable to defensive harm, the criteria for the necessity and proportionality of defensive harming, or about self- and other-defense in general. 
for a time, Jim's coercive intervention will successfully prevent Fred from seriously and wrongfully harming puppies.

Common sense morality grants prima facie permission to necessary and proportionate vigilantism that pre-emptively targets property that will be used to inflict serious and wrongful harm on others. Those who do not trust their initial judgment about F4 (perhaps because it involves animals or because it involves preventive property damage) should consider another case in which property is destroyed to prevent its use in the perpetration of serious wrongdoing.

F5: Suppose that Jim has incontrovertible evidence (including clear and compelling direct testimony) that Fred intends to carry out a mass shooting at a local music festival scheduled to take place over the next several days. Unfortunately, since Fred is a beloved and respected member of the community, the police, who are very busy preparing for the music festival, do not take Jim seriously when he reports Fred's threats of violence. Thus, Jim decides to take matters into his own hands. When Fred leaves for work the next day, Jim breaks into his house, removes or destroys all the firearms and ammunition he can find, destroys any electronic devices that could be used for planning purposes, and disables Fred's car by severely damaging its engine.

In its most morally salient aspects, F5 is analogous to F4. Again, we find Jim destroying property that would enable Fred to seriously and wrongfully harm many others, primarily because the state is reluctant to intervene. And I expect readers will share my judgment that Jim's behavior in F5 is prima facie morally permissible. Thus, we have additional support for the claim that common sense morality prima facie permits certain forms of preventative attacks on property.

To sum up: Our common sense judgments about F2, F3, and F4 justify the claim that it is prima facie morally permissible for private citizens to use coercion to prevent puppies from being seriously and wrongfully harmed. In particular, they show that in some circumstances, it is prima facie permissible to (a) use necessary and proportionate physical violence, (b) threaten necessary and proportionate physical violence, and/or (c) destroy property in order to defend puppies against both immediate and distant threats of serious and wrongful harm. And, given premise (2), they show that the same is also true with respect to other kinds of mammals.

\section{Section Three}

Cases F2, F3, and F4 elicit judgments that support the general claim-expressed in the first premise of my argument-that it is prima facie morally permissible, even for private citizens, to use coercion to prevent puppies from being seriously and wrongfully harmed. Nevertheless, I expect some people will object that cases F2-F4 are too limited to serve as the fulcrum for the rather contentious and quite general conclusions drawn in this paper. After all, in these cases the species of animal harmed remains the same, as does the purpose of inflicting the harm, and the setting in which the harm is inflicted. Others may object that cases F2-F4 are too artificial. After all, most of the actual deliberate harm inflicted on animals by humans does not result from isolated individuals abusing animals in their basements for the sake of a marginal increase in personal well-being. At any rate, if these objections cannot be met, they might discredit the conclusion I want to draw - namely, that it is prima facie permissible for private citizens, including militant animal rights activists, to use coercion to defend animals in many actual situations where they would otherwise be harmed for human benefit. 
In this section, I address these two objections. In the process, I establish the prima facie moral permissibility of at least some of the highly controversial instances of coercive direct action undertaken by militant animal rights activists. I first describe variants of $F 2$, F3, and F4 in which species, purpose, and setting are modified. I argue that these new cases are analogous, in the morally relevant respects, to cases F2-F4. They should therefore elicit moral judgments equivalent to those elicited by F2-F4. I then describe an actual case (lowa Select) in which animals were seriously and wrongfully harmed for the sake of human benefit. Since lowa Select is comparable to many actual cases, this shows that F2-F4 are not too artificial and that our intuitions about them are not idiosyncratic. I conclude by reviewing an instance of coercive direct action carried out by the Animal Liberation Front. This actual coercive intervention is comparable to the hypothetical interventions described in F2-F4. Thus, I conclude that Animal Liberation Front operations are sometimes prima facie morally permissible.

To begin, suppose Fred learns that virtually all mammals will excrete the flavor enhancing hormone he desires, as long as they are mutilated in just the right way. Consequently, he obtains several additional species to mutilate. Now consider the following case:

F6: Fred's neighbor Jim hears anguished cries emanating from Fred's basement. As a result, Jim becomes concerned and decides to peek through one of Fred's basement windows. What he sees is shocking. Fred is using a small knife to slowly mutilate a squirrel, whose body is suspended upside-down from the basement ceiling. Jim quickly concludes that something must be done. He breaks into Fred's house, rushes to the basement, and physically subdues Fred. After tying Fred to a support beam in the basement, Jim calls the police.

I expect the reader will judge, as I do, that Jim's coercive interventions in F6 are prima facie morally permissible. This suggests that the common sense moral judgments elicited by F2, F3, and F4 are not species-specific or species dependent. Given his continuing infliction of serious and wrongful harm, Fred remains liable to defensive harm even though he is now targeting squirrels. Absent countervailing moral considerations, it is permissible for private citizens to use coercion to stop people who would otherwise wrongfully mutilate squirrels.

I recognize that some people may be hesitant to extend robust moral consideration to squirrels. Thus, it should be noted that squirrels do not lack the morally salient properties that puppies possess. They are sentient animals that are physiologically comparable to puppies. And, like puppies, they are cognitively flexible creatures capable of solving novel environmental problems. ${ }^{18}$ For these reasons, the explanatory burden rests on those who would reject the extension of moral consideration to squirrels. Dissenters need to show that puppies are somehow a special case.

Of course, as Norcross notes, some people claim that "puppies count more than other animals, because [human beings] care more about them." " The idea here is that being the object of special human sympathy and concern is a property possessed by

18 For interesting recent research on problem solving and memory in squirrels see: Pizza Ka Yee Chow, PWW Lurz and Stephen E.G. Lea, "A battle of wits? Problem-solving abilities in invasive eastern grey squirrels and native Eurasian red squirrels," Animal Behaviour 137 (2018): 11-20; Pizza Ka Yee Chow, Stephen E.G. Lea, Natalia Hempel de Ibarra and Theo Robert, "Inhibitory control and memory in the search process for a modified problem in grey squirrels, Sciurus carolinensis," Animal Cognition 22 (2019): 645-55.

19 Norcross, "Puppies, Pigs, and People," 235. 
puppies that provides them with a unique kind of moral status. On this basis, it is argued, we should reject the claim that squirrels and puppies have a similar moral status.

There is much that could be said here about the challenge of grounding significant moral distinctions upon the fickle emotional sensibilities of humankind. I will just note that those who advance this view are subject to a variant of the Euthyphro dilemma. Either humans have good reasons to care more about puppies than other mammals or we do not. If we have reasons to care more about puppies than other mammals, then it is those reasons, rather than our sympathies themselves, that account for puppies' special moral status. Of course, if we have such reasons, then we should expect them to be articulable. I am not aware of any such reasons that have been clearly identified or articulated. Alternatively, if there are no good reasons to care more about puppies than other mammals, then humankind's special concern for puppies, though undeniable, is groundless. Groundless sympathy, however, hardly provides justification for disparate treatment or disparate moral consideration. ${ }^{20}$ Indeed, absent a good reason to care more about puppies than other mammals, those who object to Fred's mutilation of the former ought to, on pain of inconsistency, object to his mutilation of the latter.

Now suppose that Fred mutilates the puppies in his care for a purpose other than to obtain a flavor enhancer. It is clear enough, given our judgments about F2-F4, that coercive intervention is prima facie permissible in cases where Fred's purpose is to produce a marginal benefit that can be readily obtained by alternative means. Thus, if Fred's new purpose is to produce, say, a fur coat, then he is still liable to defensive harm. And the use of coercion to stop him from mutilating puppies remains prima facie permissible.

However, what if Fred's new purpose is to produce an extremely significant benefit that could not be obtained by other means? With this possibility in mind, consider the following case:

F7: The initial details in this case are the same as in F2. As they wait for the police to arrive, Jim asks Fred why he has been mutilating puppies. In reply, Fred tells $\mathrm{Jim}$ that he is a retired research scientist and professor emeritus at State University. After reviewing several well-designed cutting-edge studies, he has at arrived at the following hypothesis: a hormone produced by puppies subjected to prolonged and excruciating pain can be used to enhance the ameliorative powers of a promising new cancer treatment. Unfortunately, Fred no longer has lab access. Despite making many inquiries, Fred is not aware of anyone else who is attempting to collect this hormone for use in cancer research. And he has not been able to convince his erstwhile colleagues to do the work necessary to test his hypothesis. Thus, Fred has

20 Some would argue that puppies and dogs are special because human beings can enter into reciprocal social relationships with them. Is this a morally relevant difference? I should think not, largely because many kinds of non-domesticated mammals can (and occasionally do) enter into reciprocal social relationships with human beings. For one interesting example, which documents 18th century Americans' fondness for keeping squirrels as pets, see: Katherine Grier, Pets in America: A History (Chapel Hill, NC: University of North Carolina Press, 2016). Note, too, that the special relationship between humans and dogs has not prevented researchers from subjecting dogs to seriously harmful and probably wrongful experiments. For example, Syd Johnson describes experiments in which ischemic strokes are induced in dogs; as with many other kinds of harmful animal experiments, these experiments have not produced any clear ameliorative benefits for human beings. See: L. Syd Johnson, "The Trouble with Animal Models in Brain Research," in Neuroethics and Nonhuman Animals, eds. L. Syd Johnson, Andrew Fenton and Adam Shriver (Cham, Switzerland: Springer, 2020), 281. 
decided to collect the hormone himself in hopes of eventually convincing someone to incorporate it in cancer research.

When compared to its antecedents, F7 is a more vexing case. Fred's aim is not to produce a marginal benefit, but to significantly improve the ameliorative powers of a cancer treatment. Moreover, it's hardly clear that he (or anyone) has any alternative means of producing this good. Were Fred to achieve success, the harms he imposes on puppies would help to generate a tremendous benefit for human beings and all other species susceptible to cancer. Thus, Fred may have a lesser-evil justification for his puppy mutilation.

Despite these considerations, Jim's coercive interference in $\mathrm{F} 7$ is prima facie morally permissible. On reflection, it should be clear that the setting and context in F7 have significant, though indirect, bearing upon the moral calculus. Note, first, that Fred's worthy aim does not, by itself, preclude him from being liable to defensive coercion performed on the puppies' behalf. This is because many unjustifiable and wrongful harms are imposed on innocent victims by those who sincerely but unreasonably believe that they are benefiting humanity, doing God's work, or ensuring that justice is done.

To see this, suppose the following detail is added to the description of case F5: the reason Fred is planning a mass shooting is that he sincerely believes it is the only way to prevent an imminent and catastrophic attack by the space aliens who have infiltrated the apparatus of local government. Since Fred's noble purpose-to prevent a society wide catastrophe -is based on a set of transparently unreasonable beliefs, it does not justify the harms he plans to impose on others and, importantly, it does not shield him from being liable to defensive harm.

If Fred's hypothesis in F7 met basic standards of scientific rationality, then surely he would be able to convince a colleague to test it in an academic or commercial laboratory. Thus, the setting and context in F7 provide strong evidence that it is unreasonable for Fred to believe that puppy mutilation is a necessary evil. And, this, in turn, is strong evidence that Fred's behavior is wrongful (even if he manifests no ill intent). Indeed, when Jim peers into Fred's basement window, he is justified in concluding that Fred is not acting on a reasonable belief that harming puppies is necessary for the production of a significant medical breakthrough. ${ }^{21}$ If this conclusion is correct, then, despite Fred's worthy aim, Jim's coercive intervention in F8 is prima facie permissible. ${ }^{22}$

21 A question for the reader: can you imagine even considering the possibility, were you to find yourself in Jim's position, that Fred might be conducting legitimate and potentially beneficial scientific research by mutilating puppies in his basement?

22 Derek Parfit distinguishes between fact-relative, belief-relative, and evidence-relative senses in which an act can be wrong. See: Derek Parfit, On What Matters (Oxford: Oxford University Press, 2011), Volume I, 150-51. If one's actions are wrong relative to both the evidence and the facts, as Fred's actions are in case F7, this suffices to render one liable to defensive harm. However, in cases where one's actions are wrong relative to the facts but not relative to one's evidence, things appear to be more complicated. In many such cases, one has an excuse that would shield one from liability. For instance, to borrow an example from Parfit, suppose a doctor's evidence suggests that drug A will help patient $X$, but actually it makes patient X's symptoms much worse. The doctor nevertheless seems to have an excuse for prescribing A to patient $X$, even though doing so is wrong relative to the facts.

There are interesting questions about when and whether medical researchers have an excuse for conducting animal experiments that are wrong relative to the facts. Although I cannot explore these questions in detail, it nevertheless seems to me that such excuses are likely to be in short supply. This is because, given the high stakes of error for both humans and animals, medical researchers ought to be aware of the poor track record of animal experiments (which I discuss in more detail in section four); to put 
Review of case F7 provides support for the conclusion that it is prima facie permissible for private citizens to use coercive force against those who would otherwise seriously and wrongfully harm animals, regardless of the aim or purpose of the harm imposed. Even so, we might wonder whether Jim's intervention in F7 would still be prima facie permissible if Fred were conducting his research in a setting that did not immediately undermine our confidence about whether it is reasonably believed to be necessary.

Consider, then, the following case:

F8: As in F7, Fred is mutilating puppies in order to harvest a hormone that he believes will enhance the ameliorative powers of a promising new cancer treatment. This time, however, Fred is an active researcher employed by State University. He has secured grant funding for his project and is operating out of a university laboratory. In the early stages of investigation, however, Fred learns that the central claims of the research which inspired his project are actually false positives. He now knows that mutilation of the puppies in his care cannot be justified on lesser-evil grounds. Even so, in hopes of discovering something scientifically interesting, Fred resolves to continue on with the project until its funding has been exhausted, despite the fact that it is no longer reasonable to believe that it will yield beneficial knowledge.

A whistleblower in Fred's lab leaks this information to Jim, who quickly concludes that something must be done. That night, he breaks into Fred's lab and rescues the puppies. In the process of conducting the rescue, Jim destroys Fred's lab equipment, records, and computers. As he departs, Fred breaks a sewage pipe, which renders the lab unusable for the foreseeable future.

The laboratory setting of the puppy mutilation in F8 does not make it any less serious or wrongful than in cases F2-F4. Nor does it remove Fred's liability to coercive intervention on the puppies' behalf. Thus, if we judge that Jim's coercive intervention is prima facie permissible in the antecedent cases, then, as a matter of consistency, we ought to make the same judgment in F8. Indeed, aside from the setting, the details of this case mirror those of F4 in all morally relevant respects.

Again, we have a case in which Fred is seriously harming puppies for no good reason. ${ }^{23}$ The mere fact that he is doing it in a lab does not make it justifiable or excusable, even if this would suffice, in most circumstances, to justify the belief that he is conducting necessary and highly beneficial research. Nor does the fact that he is doing it on the campus of a university. Indeed, if Fred were mutilating puppies in a campus dorm room,

it another way: if they do their due diligence, there will not be many cases where animal experimentation is going to be wrong relative to the facts but justifiable relative to the researcher's evidence. Supposing, however, that a researcher does have an excuse, they are probably not liable to be harmed. Even so, animal defenders may have a lesser-evil justification for using limited and proportionate forms of coercion against them.

23 A caveat on animal experimentation: much like the pleasure Fred experiences when he eats flavor enhanced chocolate, knowledge acquired via animal experimentation has (at least in my view) intrinsic value. Even so, this value does not thereby justify the harm imposed to produce it. Indeed, I should think it uncontroversial that there are moral limits on the harms we may impose to harvest knowledge for its own sake. I do not intend to identify these limits. Certainly, however, common sense morality forbids accosting you on the street and hitting you in the face with a hammer just for the sake of collecting data about fight-or-flight responses in human beings. The (putative) intrinsic value of the knowledge obtained does not outweigh your suffering, override your interests, or trump your basic rights. To justify doing serious harm to others for the sake of knowledge acquisition, we should need to be able to show that the knowledge in question will have significant instrumental value and cannot be acquired by alternative means. 
he would be just as liable to defensive coercion as he would if he were operating out of his basement.

Nevertheless, I suspect that some readers will find that the location change in F8 makes it more difficult to arrive at a clear view about the permissibility of Jim's coercive intervention. Indeed, this location change yields two significant concerns-one having to do with the possibility that Fred's experiments are not wrongful and the other having to do with the downstream social effects of using coercion against public intuitions and their representatives - that are absent in cases F2-F7. Although these concerns warrant a reply, I will wait to address them until section four. ${ }^{24}$

At any rate, the conclusion that coercive intervention is prima facie permissible in hypothetical cases F6-F8 is significant. It undermines the objection that cases F2-F4 are too limited to support broad generalizations about the prima facie permissibility of using coercion to prevent harm to animals. We have seen that even when species, purpose, and setting are varied, it is still prima facie permissible to use proportionate and limited coercion to defend the interests of animals. Furthermore, we are now well positioned to make comparisons with the many actual cases in which animals are seriously and wrongfully harmed for human benefit.

To this end, consider the following example:

lowa Select: In the spring of 2020, the COVID-19 pandemic caused significant market disruption within the US meat industry. As a result, many farming companies were left with "excess" animals that could not be profitably killed in the usual way. lowa's largest pork producer, lowa Select Farms, dealt with the excess pigs in some of their facilities by exterminating them en masse using a process called ventilation shut down. According to Glenn Greenwald, this involves "sealing off all airways to their barns and inserting steam into them, intensifying the heat and humidity inside and leaving them to die overnight. Most pigs—-though not all-[died] after hours of suffering from a combination of being suffocated and roasted to death." 25

The harms imposed in this case are quantitatively greater (involving tens of thousands of animals) and, at a minimum, qualitatively comparable to those described in F2-F8. lowa Select thus undercuts the objection that my hypothetical cases are somehow artificial-i.e., that they are not representative of the way animals are treated, in practice, by those who harm them for human benefit. In many actual cases, businesses, institutions,

24 The change in venue in F8 also raises questions about the degree to which institutions are liable for the wrongful behavior of individuals who operate under their aegis. I will not attempt to answer this difficult question. Still, I should note that in the cases under consideration the institutions in question are actively sanctioning and supporting Fred's puppy mutilation. Thus, they too appear to be liable to defense harm (though perhaps not to the same extent as Fred). If a property owner knowingly allows their property to be used to wrongfully harm animals, this renders them at least somewhat liable to defensive action. If they do not know that their property is being used for this purpose, they may not be liable to having it damaged or destroyed. However, the property owner's lack of liability is not sufficient to show that destruction of their property is impermissible. To illustrate this, suppose that in cases F2-F4, the basement Fred uses to mutilate puppies is rented from Jane. Even if Jane is an absentee landlord who has no idea what Fred is doing, Jim seems to be prima facie justified in damaging her basement if doing so is necessary to stop Fred's imminent threat. Of course, Jane may be owed reparations for the damages Jim causes. It seems, however, that Fred is the party who would be responsible for making reparations, since it is his wrongful behavior that ultimately brought about damages to Jane's property.

25 Glenn Greenwald, "Hidden Video and Whistleblower Reveal Gruesome Mass-Extermination Method for lowa Pigs Amid Pandemic," The Intercept, May 29, 2020, https://theintercept.com/2020/05/29/pigsfactory-farms-ventilation-shutdown-coronavirus. 
and individuals operate just as Fred does in F2-F8; they wrongfully subject animals to prolonged and excruciating suffering for the sake of securing marginal benefits that could be obtained by other means.

The practices of lowa Select Farms are consistent with standard intensive confinement agricultural practices. ${ }^{26}$ Where animals are commodified, we can expect that when there are financial incentives for doing so, they will be harmed in ways that exceed what is minimally necessary to harvest their flesh, fur, or other attributes. Although I will not subject the reader to a review of the various harms associated with intensive confinement animal agriculture, it is safe to conclude that the imposition of extreme and gratuitous suffering is a predictable feature of many actual cases in which animals are already seriously and wrongfully harmed for the sake of human benefit.

By parity with our judgements about F2-F8, we should judge that it would be prima facie permissible for a bystander to use necessary and proportionate coercion to interfere with the mass extermination of pigs in lowa Select. Absent countervailing moral considerations, it is permissible to use threats, proportionate nonlethal physical violence, and property damage to prevent a barn full of pigs from being slowly suffocated and roasted alive simultaneously. And given lowa Select Farms' record of serious wrongdoing, preventive property damage that aims to stop them from acquiring more pigs also appears to be prima facie permissible. Furthermore, since similar kinds of gratuitous abuses occur throughout animal agriculture, it is reasonable to conclude that there are many actual cases where it is prima facie permissible to use coercion to prevent animals from being seriously and wrongfully harmed.

Here is one such case:

Elkton: According to an Animal Liberation Front Communique, “... on the night of August 5, [we] visited the only known fur farm in the state of Virginia, Scott Dean's DS Fox Farm in Elkton. We opened every one of the few cages at DS, giving thirteen beautiful foxes a chance at new lives in the nearby Shenandoah National Park. As we watched a few of them immediately scurry off to freedom, we damaged the machinery that allows Dean to continue his day-to-day operation confining and torturing these sensitive creatures." 27

The relevant differences between Elkton and case F4 are negligible. Indeed, since (a) foxes held in captivity on fur farms face an imminent threat of serious and wrongful harm and (b) there is no morally significant difference between foxes and puppies, the action undertaken by the Animal Liberation Front in Elkton is prima facie morally permissible. Note, too, that Elkton involves preventive property damage that, by parity with our judgment about $\mathrm{F} 4$, is also prima facie permissible.

Elkton shows that some instances of coercive direct action undertaken by the ALF are prima facie morally permissible. This is the most important conclusion of the present

26 For recent discussion of the many harms associated with factory farming, see: Matthew C. Halteman, "Varieties of Harm to Animals in Industrial Farming," Journal of Animal Ethics 1 (2011): 122-31; Stuart Rachels, "Vegetarianism," in The Oxford Handbook of Animal Ethics, eds. Tom Beauchamp and RG Frey (Oxford: Oxford University Press, 2011), 877-905; Jonathan Anomaly, "What's Wrong with Factory Farming?" Public Health Ethics 8 (2015): 246-54; Christopher Bobier, "Varieties of the Cruelty-Based Objection to Factory Farming," Journal of Agricultural and Environmental Ethics 32 (2019): 377-90.

27 "ALF Releases Captive Foxes," Animal Liberation Press Office, June 1, 2019, https: //animalliberationpressoffice.org/NAALPO/2012/08/05/alf-releases-captive-foxes-from-farm-in-northernvirginia-this-morning. 
section. Although branded as a terrorist group by governmental and media organizations, some of what the ALF does is, absent countervailing considerations, morally licit.

I will not defend the claim that all or most ALF actions are prima facie permissible. Whether or not any particular instance of coercive direct action is prima facie morally permissible will depend on the details of the case. Some of these details concern whether or not the coercion is proportionate and whether the individuals targeted are liable to defensive harm. Even so, I will not attempt to identify principles of proportionality for or liability to coercive direct action.

Clearly, bystanders - for instance, relatives of the proprietors of fur farms who have no stake in fur farming - are not liable to be harmed by the ALF. And sending mail bombs, after the fashion of Theodore Kaczynski, to people who do business with factory farms is not proportionate. Still, my aim here is not to figure out the relevant limiting principles. It is, instead, to show that common sense judgments about a range of cases, both hypothetical and actual, support the conclusion that some forms of coercion, including forcible rescue and destruction of property, are necessary, proportionate, and prima facie permissible when used against those who would otherwise seriously and wrongfully harm animals.

This conclusion, despite its modesty, is quite significant. For one thing, it makes clear that radical animal rights activists are not (or at least need not be) committed to principles, theories, or ideologies that extend beyond common sense morality. Rather than adopting an alien moral code, they are taking certain widely accepted judgments and principles to their logical (and demanding) end. Furthermore, as I will discuss in section five, this conclusion demonstrates the need for animal rights activists to engage in frank and open conversations about the aims of their movement. Finally, it shows that there is a need for the state to recognize the moral standing of animals used for human benefit and revise its laws accordingly. For if the state will not or cannot protect its most vulnerable inhabitants, some citizens will prima facie justifiably do so in its place.

\section{Section Four}

I claim that coercive intervention is prima facie permissible in case $F 8$, where Fred is mutilating puppies in a university lab as part of a research project that he knows will not produce the beneficial medical knowledge it was designed to secure. As noted above, there are two serious objections to this claim. First, there is the possibility, however remote, that the harms Fred inflicts in F8 could yield substantial human benefits. If that possibility suffices to make his behavior morally justified, then it also blocks the conclusion that coercive intervention is permissible. Second, there is the possibility that using coercion against people embedded in universities and other public-serving institutions (and/or the institutions themselves) would undermine social trust and the rule of law; this, in turn, could yield catastrophic results. This shows, one might contend, that such uses of coercion are subject to blanket prohibition (or something near enough). ${ }^{28}$

In this section, I reply to these objections. In doing so, I aim to defend a specific claim about F8, which is important to my cumulative defense of direct action, and to address general concerns about the use of coercion against researchers and institutions that serve the public. These concerns are especially salient because many widely publicized

28 I would like to thank an anonymous reviewer for raising the second objection. 
ALF operations have targeted university laboratories and researchers involved in animal experimentation. $^{29}$

I begin with the first objection. Since Fred's puppy mutilation in F8 is part of a grant funded research program conducted out of a state university laboratory, perhaps it is not unreasonable to believe that it is possible that his work will yield a significant benefit for humanity. After all, the experiments are being conducted by a serious scientist entrenched in the world of professional medical research. If provided with the liberty and tools needed to experiment, scientists often come up with surprising and beneficial findings, even when their projects do not yield the desired results. For this reason, some people think that the slightest possibility of producing a significant medical benefit is sufficient to morally justify the imposition of very serious harm on lab animals. But if it is assumed that what Fred is doing is in fact morally justifiable, then Jim's coercive intervention in F8 appears impermissible.

Common sense morality permits coercive interventions that prevent others from being wrongfully harmed. Ordinarily, it does not permit such interventions in situations where harms are not wrongfully inflicted. It is not prima facie permissible, for instance, to use force to break justly sentenced criminals out of prison, even though being confined to a prison cell is seriously harmful. Thus, those who think animal experimentation is morally justified whenever we cannot rule out the possibility that it might produce substantive human benefits (call this the low-threshold-for-likely-benefits view) are likely to maintain that Jim's coercive interventions in F8 are not prima facie permissible. ${ }^{30}$ And those who are conflicted about where to set the threshold for likely benefits may find themselves similarly conflicted about the permissibility of Jim's behavior in F8.

I will not address the question of where to set the threshold for likely benefits. This is because I do not think that animal experimentation-as a going concern, rather than the subject of idealized thought experiments-can be morally justified. I hold this view, in large part, because there are strong grounds for skepticism about the epistemic benefits of animal experimentation. As Syd Johnson points out, "the failure of $90 \%$ of all drugs brought to clinical trial is sufficiently high to call into question the value of much

29 For a useful historical overview of ALF lab raids see: Peter Young, Liberate: Stories and Lessons on Animal Liberation above the Law (Warcry Communications, 2019). For a detailed perspective on several early ALF lab raids, see: Ingrid Newkirk, Free the Animals: The Amazing True Story of the Animal Liberation Front (New York: Lantern Books, 2012).

30 I am not aware of any philosophers who have explicitly defended and articulated this view. I think, however, that it would not be unfairly attributed to Carl Cohen on the basis of (a) his utilitarian argument for markedly increasing animal experimentation and (b) his specific remark that "the wide and imaginative use of live animal subjects should be encouraged rather than discouraged." See: Carl Cohen, "The Case for the Use of Animals in Biomedical Research," The New England Journal of Medicine 314 (1986): 868. Moreover, the low-threshold-for-likely-benefits view seems to me to be implicit in the thought and practice of a substantial number of the people who fund and conduct animal experiments. For instance, many of Harry Harlow's maternal deprivation experiments, which involved placing baby rhesus monkeys in solitary confinement devices to simulate the effects of depression, are difficult to justify in terms of any expected or actual therapeutic benefits. Martin Stephens' early review of the literature on isolation and deprivation experiments concluded that "over 7000 animals were subjected to procedures that induced distress, despair, anxiety, general psychological devastation, or even death ... [the results of which] have had little impact on clinical practice, and the potential for future advances seems limited." See: Martin L. Stephens, "Maternal Deprivation Experiments in Psychology: A Critique of Animal Models," A report prepared for the American, New England, and National Anti-Vivisection Societies (1986), 81. Despite this, some researchers continue to run maternal deprivation experiments. For one example, see: Daniel Gottleib and John Capitanio, "Latent Variables Affecting Behavioral Response to Human Intruder Test in Infant Rhesus Macaques (Macaca mulatta)," American Journal of Primatology 75 (2013): 314-23. 
preclinical research using animal models." ${ }^{31}$ This suggests that animal experimentation is not a reliable method for producing instrumentally valuable knowledge. Indeed, Mylan Engel goes further and argues that "animal-based research is known to be an extremely unreliable method for determining the origin, pathology, and proper treatment of human disease" and thus "fails to provide the epistemic benefits needed to [morally] justify its continued use." 32

Animal experimentation's explicit purpose is to produce instrumentally beneficial knowledge. Given its poor record of producing such knowledge, the burden of proof is on those who think Fred's behavior in F8 is not wrongful. Indeed, the available evidence shows, at a minimum, that the low-threshold-for-likely-benefits view is not a reasonable default position. Thus, its advocates face the challenge, with respect to F8, of justifying the claim that the extremely remote possibility of producing unspecified benefits from what appear to be unnecessary experiments suffices to justify the imposition of serious harms on puppies. I do not see how this challenge can be met. When it comes to imposing serious harms on others, we should follow Aristotle's advice: trust the appearances. If the imposition of harm appears unnecessary, then, unless we are given a strong reason to think otherwise, we should take it for granted that it is, in fact, unnecessary (and therefore morally unjustifiable).

It is worth noting, at this point, that for those who agree with me about the general epistemic unreliability of animal experimentation, nearly all animal experiments are going to look an awful lot like F8; that is, they are going look analogous to the many other cases in which serious harm is unnecessarily imposed on animals. As we have seen, coercive intervention is prima facie permissible in such cases. Thus, I think there is an argument to be made for the view that nearly everyone who experiments on animals is liable to be defensively harmed.

Nevertheless, having clarified my views on animal experimentation, I will not attempt to defend them any further. I acknowledge that my position is controversial even among those who are otherwise prepared to extend significant moral consideration to animals. ${ }^{33}$ Thus, I will grant to the dissenting reader that some animal experiments are reasonably believed to be necessary for the production of significant human benefits. And I will grant that those who inflict serious harm on animals (directly or indirectly) in the process of performing such experiments are not thereby liable to be harmed. The point I wish to emphasize here is that when a research project involves imposing serious and wrongful

31 Johnson, "The Trouble with Animal Models," 272.

32 See: Mylan Engel, "Epistemology and Ethics of Animal Experimentation," in Applied Epistemology, ed. Jennifer Lackey (Oxford: Oxford University Press, 2021), 92. Engel argues as follows: First, he notes that both internalist and externalist epistemologists agree that if a method of belief formation is known to be unreliable on the basis of track-record evidence, then beliefs produced by that method are not justified. $\mathrm{He}$ then demonstrates that animal experimentation in biomedical research has an extensive track record of unreliability. Since methods known to be unreliable are not sources of justification and since animal experimentation is known to be unreliable, animal experimentation is not a source of justified belief or knowledge. But if animal experimentation has any benefit for humanity, it must be an epistemic benefit, since the point of carrying out these experiments is to acquire instrumentally valuable knowledge that can be applied to treat or prevent human ailments. On these grounds, Engel concludes that it is not reasonable to believe that animal experiments are a necessary evil.

33 For instance, R.G. Frey accepts that many (perhaps most) harms imposed on animals for human benefit are morally unjustifiable. But he is a consistent defender of animal experimentation in medical research. For one recent work where he outlines these views, see: R.G. Frey, "Animals and their Medical Use," in Contemporary Debates in Applied Ethics, eds. Andrew I. Cohen and Christopher Heath Wellman (Malden, MA: Blackwell, 2019), 91-104. 
harm upon animals, coercive intervention is prima facie permissible. There is no special exemption or excuse for researchers who knowingly and willingly impose wrongful harms on animals (as Fred does in F8). Once this point is acknowledged, however, we can table questions concerning the precise conditions under which animal experimentation is wrongful.

Of course, some people who agree that Fred acts wrongly in F8 will still balk at the suggestion that Jim's coercive intervention is prima facie permissible. This is because, to return to the second objection mentioned above, they worry that using coercion against public-serving institutions (and the individuals embedded within them) could have very bad results. Indeed, they think the use of coercion in cases such as F8 threatens to undermine the rule of law, democratic norms, and/or basic social trust. On the assumption that we should not do things that seriously elevate these threats, it is not prima facie permissible for $\mathrm{Jim}$ to coercively intervene in F8. ${ }^{34}$ And, more generally, it is not prima facie permissible for animal rights activists to adopt coercive direct action as a tactic for remediating the wrongful treatment of animals in and by public-serving institutions.

Why should we think the use of coercive direct action could have these bad effects? The most immediate answer is that, in a democratic society committed to the rule of law, citizens use legislative processes to resolve substantive moral and political disagreements. ${ }^{35}$ Although democratic societies can tolerate infrequent use of illegal coercive interventions to support and enforce consensus moral norms (e.g., rough justice for child molesters), countenancing the use of illegal coercive interventions in attempts to "settle" significant and divisive moral/political disputes would be seriously destabilizing. And it would be even more destabilizing when the targets of such coercion are institutions that serve the public; this is because many citizens plausibly perceive themselves to have a stake in such institutions and therefore assign them significant symbolic value. Thus, absent some kind of limiting principle, the use of coercive direct action against public-serving institutions poses a strong risk of provoking a violent response in kind, incentivizing additional law breaking and undercutting social trust.

In reply to this objection, I should first like to acknowledge that it is very difficult to identify the conditions under which a member of a democratic society may permissibly violate the law in the service of promoting the good, preventing harm, or ensuring that justice is done. I think this is one of the most important challenges in political philosophy. For this very reason, however, I do not think there are special concerns about the claim that it is permissible to use coercive direct action to prevent the wrongful harm of animals in university laboratories (or, for that matter, in intensive confinement facilities and other public-serving institutional settings). This is because anyone who defends the permissibility of violating democratically enacted laws in the service of promoting the good, preventing harm, or seeking justice must address the problem of finding and articulating a limiting principle that preserves the rule of law and basic social trust. And contrary to what Socrates claims in Crito, I expect readers will agree that it is sometimes permissible to violate the law in the service of these ends.

34 I can imagine someone who agrees that the research in F8 is morally unjustifiable nevertheless saying something like the following: "Sure, Fred is liable, in some sense, to defensive harm ... but we can't have people assaulting scientists and destroying their labs whenever they judge that their research is immoral ... allowing even a little bit of that would undermine the work of the university, which we all agree is one of society's most important institutions."

35 I assume here that most readers will be members of democratic political communities. 
There is, for instance, widespread support for the use of nonviolent civil disobedience-which is, by definition, a form of illegal direct action-as a means to protest against social injustice. ${ }^{36}$ But civilly disobedient protest can also have the objectionable effects associated with coercive direct action; for example, it too may provoke violence, incentivize additional law breaking, and threaten social trust. And civil disobedience is rarely employed to enforce consensus moral norms. Instead, it is typically used to address divisive moral and political conflicts by broadcasting perceived injustices and publicly articulating grievances. This is often done with the aim of building a consensus that has not yet been realized.

That civil disobedience is sometimes permissible is the default position among political philosophers. Once this is granted, however, it becomes difficult to see why there should be a blanket prohibition (or something thereabouts) on using illegal coercive measures to defend animals. Why is one form of lawbreaking permissible (and perhaps even laudable) while the other is not? Those who would insist that there is a blanket prohibition on coercive direct action owe us an answer. And the answer cannot be that coercive direct action (a) involves law breaking for the purposes of addressing a controversial moral/political cause or (b) that it has the potential to incentivize additional law breaking and/or threaten social trust. As noted above, these are features of many justifiable acts of civil disobedience.

For instance, the 1963 Birmingham campaign-organized by the Southern Christian Leadership Conference to protest against racial segregation in Birmingham, Alabama-had both of the aforementioned features. The campaign employed marches, sit-ins, and other forms of illegal assembly aimed at advancing the locally controversial cause of desegregation. And it provoked a response that seriously threatened the stability of the social order; members of the Ku Klux Klan and other opponents of desegregation set off several bombs that year, including one at the 16th Street Baptist Church (a meeting place for civil rights activists) that killed four children. ${ }^{37}$ Despite this, the Birmingham campaign is a paradigm instance of justifiable civil disobedience.

Perhaps, then, the morally relevant difference between civil disobedience and coercive direct action is that the latter is violent. It is not implausible to think that violent acts harm their targets more than civilly disobedient acts and are thereby more likely to provoke further violence in response. This idea, however, does not withstand scrutiny. Although a physical attack on one's person or property is undeniably harmful, a sustained campaign of nonviolent harassment can be significantly worse. Indeed, one can easily imagine many cases where civil disobedience would be more harmful to more people than the use of constrained and proportionate coercive force.

Compare wrestling Fred to the ground and tying him up to, say, staging a year of road-blocking protests in front of his place of business. Such protests will not only have significant adverse effects on Fred, they will also have significant adverse effects on innocent, non-liable customers, pedestrians, and owners of adjacent businesses. When

36 Kimberly Brownlee provides a helpful overview of the philosophical discourse on civil disobedience and a discussion of the conditions under which it is justifiable. See: Kimberly Brownlee, "Civil Disobedience," in ed. Edward Zalta, The Stanford Encyclopedia of Philosophy, Fall 2017, https://plato.stanford.edu/ archives/fall2017/entries/civil-disobedience.

37 For additional information on the Birmingham bombings and their aftermath, see: Doug Jones, Bending Towards Justice: The Birmingham Church Bombing that Changed the Course of Civil Rights (New York: St. Martins Press, 2019). 
civil disobedience significantly harms non-liable innocents, however, it may be even more likely to produce socially destabilizing and disproportionately violent responses.

Alternatively, perhaps the relevant moral difference between civil disobedience and coercive direct action is that the former, unlike the latter, demonstrates deference to the rule of law. This is because civil disobedients expect and accept punishment for their illegal behavior. Indeed, appealing to examples of justifiable civil disobedience from the US civil rights movement, some philosophers have claimed that a lawbreaker's willingness to accept punishment is a necessary condition on her illegal behavior counting as civilly disobedient. ${ }^{38}$ Let us call this the acceptance condition on justifiable civil disobedience.

Satisfaction of the acceptance condition no doubt enhances the expressive power of civilly disobedient acts. One cannot very easily dismiss the sincerity of a disobedient citizen who makes a public demonstration of accepting sanction for his crimes. Nor can one easily dismiss his actions as an attack on the rule of law itself. Those who publicly and willingly submit to punishment appear to demonstrate fidelity to the rule of law and to the basic conflict resolution procedures that are partly constitutive of a democratic political community.

By contrast, the militant animal rights activists who use coercion against universities and other public-serving institutions typically seek to evade sanction. Thus, their actions do not satisfy the acceptance condition. Does this show that they pose a challenge to the rule of law that is distinct from the challenges posed by justified civil disobedience? And, does it show, in turn, that there is a clear and significant moral difference between lawbreaking qua justified civil disobedience and lawbreaking qua coercive direct action?

I think not. For one thing, philosophers of civil disobedience disagree about whether satisfaction of the acceptance condition is a necessary (or even typical) feature of justified acts of civil disobedience. Indeed, several of the most prominent figures in the civil disobedience literature-including Kimberly Brownlee, David Lefkowitz, and Piero Moraro-reject the acceptance condition. ${ }^{39}$ Thus, the fact that coercive direct action undertaken by militant animal rights activists rarely meets the acceptance condition hardly seems a decisive point against its prima facie permissibility.

Suppose it is granted, however, that justified acts of civil disobedience must meet the acceptance condition. This still will not show that civil disobedience can be morally differentiated from coercive direct action in a way that would support a blanket prohibition of the latter. After all, the defender of coercive direct action can take shelter behind the acceptance condition; that is, he can grant that lawbreaking in the service of the good-whether peaceful or violent-is permissible only when lawbreakers willingly submit to punishment. He would thus maintain that those who use coercion to stop animals from being wrongfully harmed in laboratories (or other public-facing institutions) should, upon completion of their task, confess to their crimes and accept their punishment. One can imagine, for instance, an animal rights activist standing before a court of law and saying "I rescued those monkeys, I destroyed that lab, and l'd do it again in a heartbeat...I could no longer just stand by ... someone had to emancipate the innocent from the

38 For an influential defense of this view, see: John Rawls, A Theory of Justice (Cambridge, MA: Harvard University Press, 1971), 363-91.

39 See: Kimberly Brownlee, Conscience and Conviction: The Case for Civil Disobedience (Oxford: Oxford University Press, 2012); David Lefkowitz, "On a Moral Right to Civil Disobedience," Ethics 117 (2007): 202-33; Piero Moraro, "On (not) Accepting the Punishment for Civil Disobedience," Philosophical Quarterly 68 (2018): 503-20. 
hands of the deranged ... I plead guilty and take full responsibility." 40 Although I do not endorse the acceptance condition, I should think that if its satisfaction can deflect the charge that civil disobedience undermines the rule of law, then the same is true with respect to necessary and proportionate coercive direct action. ${ }^{41}$

Given the points made above, it is inconsistent to hold that civil disobedience is permissible while endorsing blanket prohibition of coercive direct action. Although I recognize the risks that attend to its use, I see no strong reason to conclude, in advance of case-specific contextual details, that it is impermissible to use coercive direct action to intervene in the moral and political disputes that emerge in a democratic society. Instead, I maintain that its moral permissibility is sensitive to the circumstances of the situations in which it is deployed. And, as we have seen, some situations involving the abuse of animals render prima facie permissible the use of necessary and proportionate coercive interventions. Of course, I should remind the reader that the conclusion I defend is, by design, a rather limited one; I hold that it is prima facie permissible (in most instances) to use coercion to prevent animals from being seriously and wrongfully harmed. This view is compatible with the possibility that most coercive actions undertaken for this purpose are not ultima facie permissible.

For all that I have said in the preceding paragraphs, I accept that the potential for coercive direct action to damage to the rule of law and the social order yields prima facie reasons against its use. And it is possible that these reasons are so weighty that they often end up overriding the prima facie reasons in favor of such action. I am inclined to think otherwise. However, as I argue in the next section, there are additional considerations that may rule out the ultima facie permissibility of many prima facie permissible instances of coercive direct action. It would not undermine any of the central claims of this essay to allow a couple of additional speculative considerations to serve as reasons for sometimes concluding that coercive direct action is not ultima facie permissible. The key point here is just that these considerations do not suffice to warrant blanket prohibition of its use, even in cases where the targets are public-serving institutions.

\section{Section Five}

When evaluating the use of coercive direct action by participants in the animal rights movement, two important questions emerge. First, what is the basic goal of those who

40 A point of comparison: Henry Shue claims that a similar burden should fall on those who justifiably use torture-which, he argues, should never be legal-for the sake of preventing a catastrophe, such as the detonation of a ticking time bomb in a major city center. These persons should willingly accept punishment for the sake of upholding the rule of law and ensuring that the use of torture as an interrogation tactic remains taboo. Even so, Shue thinks the balance of reasons would typically support issuing suspended sentences to justified torturers. Perhaps the same is true in cases where activists justifiably use coercion to defend animals. See: Henry Shue, "Torture," Philosophy and Public Affairs 7 (1978): 143.

41 It is worth noting, in addition, that the coercive interventions considered here have a very different goal than paradigm cases of justified of civil disobedience. While the latter are largely focused on the communication of grievances, arguments, and critiques, the former are focused on rescue and prevention (although communication of grievances might be an expected benefit or a secondary aim of these actions). Their fundamentally different aims may ultimately yield different conditions on their justifiability; I presume, for instance, that the direct prevention of imminent harm usually has greater moral significance than the civilly disobedient activists' expression of, say, his opposition to a political figure. While communicating a grievance may prevent wrongful harm in an indirect way, rescue and sabotage, when successful, do so directly. Thus, although I cannot sort out the details here, I think that there are less stringent conditions on the justifiability of illegal acts that aim at rescue from and/or direct prevention of wrongful harm. 
undertake coercive direct action for the sake of animals? Second, is coercive direct action an effective way to achieve that goal? If the goal is simply to reduce harm to animals in an immediate and substantive way, then coercive direct action will often be an effective measure. If, however, the goal is to motivate others to embrace an animal rights worldview or to convince political communities to adopt policies consistent with that worldview, then use of coercion is much less likely to be effective.

I presume that most animal rights proponents share both of these goals. When we consider whether to undertake coercive direct action, however, it appears that the goal of preventing immediate harm is in tension with the goal of producing an animal friendly future society (and thereby preventing serious and wrongful harm to animals in the long term). This is because coercive direct action tends to reinforce negative stereotypes about animal rights activists; namely, that such individuals are violent, antisocial, holier-than-thou, and so forth. Recent empirical studies suggest that even people who are inclined to support a given social movement (or who see themselves as sharing its values) will nevertheless fail to align their behaviors with that movement due to negative stereotypes about its activist leaders and/or an inability to sympathize with its extreme tactics. ${ }^{42}$ Moreover, as Maclnnis and Hodson demonstrate, existing social bias against animal rights activists is already significant. ${ }^{43}$

For these reasons, animal rights activists must seriously consider whether the short-term gains of coercive direct action can justify its costs. In many cases, I think they cannot. For instance, actions such as writing graffiti, engaging in minor property damage, and issuing anonymous threats to medical researchers are likely to bolster negative sentiments about the animal rights movement without producing substantive countervailing benefits for animals. In view of the above considerations, I propose that animal rights activists should not consider using coercive tactics, even when prima facie permissible, unless (a) it is reasonable to think that doing so will come at little cost to the broader animal rights movement or $(b)$ it is reasonable to think their use will prevent harms so significant that the broader movement can bear any resulting costs.

I will not attempt to systematically adjudicate the question of which instances of direct action have satisfied conditions (a) or (b). It is likely, however, that some have satisfied one or both of these conditions. For instance, small-scale rescues of animals from fur farms often fail to generate significant media coverage, perhaps because they tend involve limited numbers of animals and limited property damage. Since these actions do not find their way into national or global news cycles, they are unlikely to discredit or damage the broader animal rights movement. Thus, they may satisfy (a).

\section{Conclusion}

I began this essay by presenting an argument for the conclusion that it is prima facie morally permissible, in most instances, to use coercion to prevent mammals such as cows, pigs, sheep, and mice from being turned into food, clothing, or experimental

42 See, for instance: Matthew Feinberg, Robb Willer and Chloe Kovacheffa, "The Activist's Dilemma: Extreme Protest Tactics Reduce Popular Support for Social Movements," Journal of Personality and Social Psychology 119 (2020): 1086-111; NY Bashir, Penelope Lockwood, Alison Chasteen, Daniel Nadolny and Indra Noyes, "The Ironic Impact of Activists: Negative Stereotypes Reduce Social Change Influence," European Journal of Social Psychology 43 (2013): 614-26.

43 Cara C. MacInnis and Gordon Hodson, "It Ain't Easy Eating Greens: Evidence of Bias Toward Vegetarians and Vegans from both Source and Target," Group Processes Intergroup Relations 20 (2015): 721-44. 
research subjects. After using section one to clarify my terms, in section two I defended the first premise of my argument-namely, that it is prima facie morally permissible to use coercion to prevent puppies from being seriously and wrongfully harmed. I did this by appealing to judgments of common sense morality. These judgments were elicited by reflection on several variants of Alastair Norcross' Fred case. In section three, I showed that the claim about puppies generalizes. Across a range of additional cases of animal abuse, both hypothetical and actual, I found that necessary and proportionate coercive intervention is prima facie permissible. This result supports the conclusion of my argument, which, if correct, has significant implications for animal ethics.

First, it suggests that many instances of coercive direct action undertaken by the Animal Liberation Front (and other militant animal rights activists) are prima facie morally permissible. I am not aware of any work in animal ethics, aside from the polemical writings of Steve Best, that explicitly argues for this claim or even conditionally defends the actions of the ALF. ${ }^{44}$ Second, since this claim ultimately rests on common sense judgments about permissible responses to puppy mutilation, it turns out that seemingly radical animal rights principles are embedded in ordinary moral thought. As a result, even if, as I argue in section five, many ALF actions are counterproductive, self-defeating, or ultima facie impermissible, we should view them as understandable (and potentially excusable) responses to the gratuitous harms regularly imposed upon animals on the farm and in the lab.

When warnings go unheeded and pleas for mercy are ignored, many conscientious individuals will not stand by. They will instead gravitate toward militant resistance. And this suggests, third, that animal ethicists have a responsibility to carefully scrutinize the case for using coercive direct action to defend animals. There remain significant questions about when, if ever, coercive direct action is ultima facie permissible (or perhaps even required) and how to address the inherent tensions between using force to stop immediate abuses and activists' long-term goal of promoting an animal rights worldview. With these questions in mind, I offer this essay as an invitation to further conversation. My hope is that others will join me in addressing the moral complexities of militant direct action.

Acknowledgments: I would like to thank five colleagues for providing invaluable feedback on this paper. Many of their suggestions have been incorporated into the text. Nevertheless, since the views defended here may provoke significant backlash, it seems inadvisable to name these people. Indeed, several of them have expressed reasonable concerns about having their names directly linked to this paper.

44 Best, "It's War." 